\title{
Produção de membranas de polipropileno e carvão para adsorção de azul de metileno
}

\section{Production of membranes of polipropylene and charcoal to adsorpt metilene blue}

\author{
Andressa M. A. Neves ${ }^{1}$; Rafaela Nadiele Silva ${ }^{1}$; Kássia Graciele dos Santos ${ }^{2}$; Rafaela Cristina Sanfelice ${ }^{2}$ \\ ${ }^{1}$ Aluna do Curso de Engenharia Química, Universidade Federal do Triângulo Mineiro, Uberaba, Minas \\ Gerais, Brasil. E-mail: ademirjsfilho@hotmail.com; rahfa-chan@hotmail.com \\ 2 Professora do Programa de Mestrado em Inovação Tecnológica, Universidade Federal do Triângulo \\ Mineiro, Uberaba, Minas Gerais, Brasil. E-mail: kassiagsantos@gmail.com; rafaela.sanfelice@uftm.edu.br
}

RESUMO: Nos últimos anos, com o desenvolvimento da agroindústria, os resíduos gerados tornaram-se motivo de preocupação. Efluentes com corantes industriais podem contaminar águas, prejudicando a saúde humana e o meio ambiente. Assim, este trabalho propõe o aproveitamento do carvão do bagaço de cana para a produção de membranas com polipropileno, visando a adsorção de corantes de indústrias têxteis. Foram analisados equipamentos para definir-se qual possibilitava a criação de membranas com as características buscadas: Mufla, Analisador de umidade via infravermelho e Estufa. Além disso, parâmetros foram analisados: variações de tempo, temperatura e composição. "Depois de obtidas, as membranas foram lavadas e tiveram as características visuais determinadas por análise microscópica. Analisou-se o comportamento das membranas na presença de uma solução de azul de metileno através de testes de adsorção. A partir dos testes realizados, observou-se que a Mufla foi o equipamento ideal para produzir as membranas, pois o polipropileno fundiu-se totalmente no forno e após retirado, solidificou-se, retendo o carvão na membrana. As características esperadas para as membranas foram: porosas, polipropileno fundido e carvão aderido. As condições de operação foram: $90 \%$ de polipropileno e $10 \%$ de carvão em sua composição e 13 minutos dentro da Mufla. Ainda, as membranas apresentavam distribuição dos componentes e poros de forma heterogênea através das análises microscópicas.

Palavras-chave: Adsorção de corantes; Bagaço de cana; Carvão vegetal; Membranas poliméricas.

\begin{abstract}
In the last few years, due to the development of the agro industry, the waste generated became a reason of concern. Effluents with industrial dye can contaminate waters, impairing the human health and the environment. Based on that, this work proposes the use of the coal from sugarcane bagasse to produce membranes with polypropylene, aiming the adsorption of dyes. Three equipments were analyzed to decide which one could made possible to create membranes with the desired specifications: Electric oven, Infrared moisture analyzer and Lab stove. Besides that, parameters were analyzed: time, temperature composition. After obtained, the membranes were washed; the permeability and visual characteristics were obtained, by microscopically analysis. Finally, the membranes behavior in the presence of methylene blue solution was analyzed, by adsorption tests. The Electric oven was the ideal equipment to produce the membranes because the polypropylene totally merged inside the oven and, after being removed from it, has solidified, retaining the coal on the membranes. The sought membranes characteristics were: porous, molten polypropylene and coal retained. The operational conditions that allowed this result were: membranes with $90 \%$ of polypropylene and $10 \%$ of coal and that stayed 13 minutes inside the oven. It was also verified that the membranes had a heterogeneous distribution of its components and pores by microscopic analysis.
\end{abstract}

Keywords: Dye adsorption; Membrane; Methylene blue; Sugarcane Bagasse. 


\section{INTRODUÇÃO}

Nos últimos anos, o crescimento do setor agroindustrial propiciou aumento na geração de resíduos, aumentando consequentemente a preocupação com o reaproveitamento destes. Outra fonte de contaminação do meio ambiente é a geração de efluentes industriais. Os rejeitos industriais apresentam elevada quantidade de metais pesados, corantes e compostos orgânicos altamente tóxicos para os solos, águas e para o ser humano (PAULINO, 2008). Neste contexto, os processos têxteis são grandes consumidores de água e corantes sintéticos, gerando altos volumes de efluente com alta carga orgânica e forte coloração devido à presença de corantes que não são fixados às fibras (ROYER, 2008).

O azul de metileno é um corante catiônico muito utilizado na indústria têxtil para o tingimento de algodões e lãs. Além disso, é aplicado em tinturas para cabelo, tingimento de papéis, como indicador redox e em outras aplicações (OLIVEIRA et al., 2013; YI; ZHANG, 2008). A contaminação dos corpos hídricos por esse corante promove alteração na coloração e uma diminuição da transparência da água, interferindo na penetração da luz solar, dificultando a fotossíntese da vegetação aquática (RAFATULLAH et al., 2010) além de causar efeitos prejudiciais à saúde (SENTHILKUMAAR et al.,2005; GHOSH; BHATTACHARYYA, 2002). A adsorção é um processo muito eficiente para remoção de corantes (XING; LIU, 2010; MCKAY, 1999) sendo o carvão ativado o adsorvente mais utilizado comercialmente, mesmo com o custo ainda sendo alto (BHATTACHARYYA, 2006; ROBSON, 2001).

A estrutura do carvão ativado é definida como lâminas de anéis aromáticos, com espaços entre as mesmas, que são poros formados durante o processo de produção. Nesse material, há uma pequena quantidade de heteroátomos ligados aos átomos de carbono, como hidrogênio, oxigênio, nitrogênio e outros compostos gerados em sua manufatura (PEREIRA, 2010). Alguns dos materiais que possuem alto teor de carbono podem ser usados para produzir carvão ativado. Assim, os precursores utilizados são cascas de coco, de arroz, de nozes, carvões minerais, madeiras, turfas, resíduos de petróleo, ossos de animais, caroços de pêssego, de damasco, de amêndoa, de ameixa, de azeitona, grão de café, e o objeto de estudo deste trabalho, o bagaço de cana-deaçúcar (CLAUDINO, 2003; GIUSTO, 2015). O carvão apresenta alta porosidade e é capaz de coletar seletivamente gases, líquidos ou impurezas para o interior dos seus poros, apresentando, portanto, um excelente poder de clarificação, desodorização, purificação de líquidos e gases. Diante disso, os usos mais comuns para o carvão ativado são: a elaboração de filtros para adsorção de gases e para tratamento de águas, onde o carvão se destaca por reter nos seus poros impurezas e elementos poluentes. (FREITAS; BUENO, 2013). Assim, a aplicação do carvão ativado em efluentes têxteis está voltada, principalmente, para a remoção da coloração e não para a degradação da matéria orgânica presente nos efluentes lançados no meio ambiente (COSTA et al., 2008). Devido a isso, neste trabalho, o processo adsortivo desse material foi avaliado quanto a remoção da coloração do corante azul de metileno, denominado como contaminante orgânico, utilizado no tingimento de tecidos.

O polipropileno (PP) é um termoplástico semicristalino conhecido por seu baixo custo, sua elevada resistência química a solventes, fácil moldagem e de coloração, por alta resistência à fratura e estabilidade térmica. Várias são as aplicações deste polímero, tais como em brinquedos, recipientes para alimentos, remédios, produtos químicos, carcaças 
para eletrodomésticos, fibras, material hospitalar esterilizável, entre outros (ZEN et al., 2006). É um polímero termoplástico derivado do propeno e pode ser moldado utilizandose apenas aquecimento (INDUPROPIL, 2018), o que permite o seu reaproveitamento na forma de reciclagem. As principais aplicações do polipropileno, sem definir seu tipo, são: embalagens, rótulos, fibras para tecidos, artigos de papelaria, equipamentos de laboratório, peças automotivas, utensílios domésticos, móveis, sacos para grãos, copos descartáveis, seringas de injeção, tampas de garrafa PET ou de vidro, peças de eletrodomésticos, objetos para construção civil, recipientes resistentes a solventes, ácidos e bases, mantas absorventes de material oleoso e objetos diversos (RESO SOLUÇÕES AMBIENTAIS, 2018). O polipropileno possui boa resistência química e física, seu alto ponto de fusão (em torno de $180^{\circ} \mathrm{C}$ ).

De uma maneira geral, uma membrana é uma barreira que separa duas fases e que restringe total ou parcialmente o transporte de uma ou várias espécies químicas presentes nas fases (BORGES et al., 2006). Para que ocorra o transporte de uma espécie através de uma membrana é necessária a existência de uma força motriz, que pode ser provocada por vários tipos de gradientes: de concentração, de potencial elétrico, de pressão de vapor e de pressão hidráulica (BORGES et al., 2006). As membranas sintéticas comerciais são produzidas a partir de duas classes distintas de material: os materiais orgânicos (em sua grande maioria polímeros) e os inorgânicos, como metais e cerâmicos (BORGES et al., 2006). Entre os materiais orgânicos e poliméricos, o polipropileno se destaca por suas características, tais como baixo custo (ZEN et al., 2006). Neste trabalho, as membranas produzidas foram feitas com carvão e polipropileno, e inicialmente inseridas em um equipamento para fundir o polipropileno e proporcionar a adesão do carvão à superfície da membrana.

A remoção de corantes da água pode ser feita através de um processo simples de adsorção, no a molécula adsorvida é denominada adsorvato e o sólido, o qual fica suspenso ou em contato com a água, é o adsorvente. Essa técnica é simples pois não requer alto custo de aplicação, necessita de baixo consumo energético, e, em se tratando de adsorção com carvão ativado, há a possibilidade da reutilização do carvão (FERNANDES et al., 2016). Diante disso, a adsorção tem sido amplamente aplicada na remoção de corantes de efluentes provenientes de indústrias têxteis, de couro, etc. (BHATNAGAR, 2010). Após confeccionadas, o comportamento adsortivo das membranas foi estudado através de testes de adsorção com solução de corante azul de metileno.

Neste contexto, o presente trabalho objetivou realizar a produção de membranas compostas de polipropileno e carvão oriundo do bagaço de cana para adsorção de azul de metileno para posterior aplicação em indústrias têxteis. Para isso, estudou-se qual a melhor composição para as membranas e o melhor equipamento para a produção das mesmas. Analisou-se o comportamento dessa com vários teores de carvão e polipropileno. Por fim, testes de adsorção foram realizados a fim de testar a eficiência de remoção do corante.

\section{PROCEDIMENTOS EXPERIMENTAIS}

$\mathrm{Na}$ preparação de membranas, os materiais usados foram carvão em pó proveniente da pirólise de bagaço de cana-de-açúcar e polipropileno em formato de grânulos doado de uma empresa privada de reciclagem localizada na cidade de Ribeirão Preto, SP. O polipropileno foi triturado em um moinho de facas tipo Wilve e posteriormente foi peneirado em uma peneira de mesh igual a $12(0,0017 \mathrm{~m}) \mathrm{com}$ o 
objetivo de obter um material mais fino e com granulometria controlada. Para a determinação do equipamento ideal para a síntese da membrana foram realizados testes em três equipamentos diferentes: Mufla, Estufa e Analisador de umidade via infravermelho em uma faixa 433,5 a 453,15 K, valores próximos à temperatura de fusão do polipropileno. Nos testes realizados na Mufla e na Estufa, o polipropileno foi distribuído em um molde circular de silicone. Para o Analisador de umidade via infravermelho, foi preparada uma amostra de menor quantidade pois o aparelho apresenta uma balança muito sensível, uniformemente distribuída no próprio prato do equipamento. Após definido o equipamento ideal para a produção das membranas, realizou-se um planejamento experimental, a fim de se obter as condições de produção adequadas. A Tabela 1 apresenta os testes detalhados para cada equipamento.

Tabela 1 - Descrição dos testes realizados em cada equipamento.

\begin{tabular}{cccc}
\hline Equipamento & Massa $(\mathrm{Kg})$ & Tempo $(\mathrm{s})$ & Temperatura $(\mathrm{K})$ \\
\hline Analisador de umidade & $9 \mathrm{E}-03$ & $5,0 \mathrm{E} 02$ & 433,15 \\
\hline Estufa & $9 \mathrm{E}-03$ & $1,5 \mathrm{E} 03$ & 433,15 \\
\hline Mufla & $6 \mathrm{E}-03$ & $1,8 \mathrm{E} 02$ & 443,15 \\
\hline
\end{tabular}

Para a determinação da temperatura e tempo ideais de permanência das membranas no equipamento, foram realizados testes com polipropileno puro na mufla pois este foi o equipamento que proporcionou a obtenção das membranas com as características buscadas (Descrito em detalhes nos resultados). Assim, o método empregado para a fabricação de membranas consistiu no uso um molde de silicone circular preenchido com diferentes proporções mássicas de carvão e polipropileno. Em seguida, os moldes foram levados à mufla previamente aquecido na temperatura desejada e mantido por diferentes tempos. Após o término do tempo de formação das membranas, elas foram retiradas do forno e deixadas na bancada até atingir a temperatura ambiente. A Tabela 2 apresenta diversas condições usadas na fabricação das membranas. A membrana de número 8 foi a que mais se aproximou das características desejadas. Foram produzidas 45 réplicas desta membrana.

As membranas que quebraram durante sua obtenção e as que apresentaram poros muito grandes e visíveis a olho nu foram descartadas. As demais foram lavadas três vezes com água destilada com o intuito de retirar a massa de carvão que não ficou aderida ao polipropileno. Além disso, visando evaporar a água destilada que ficou retida nos poros das membranas durante a lavagem, essas foram levadas a estufa por um dia a $378,15 \mathrm{~K}$, e suas massas foram pesadas antes e após esse tempo na estufa.

Para analisar microscopicamente as membranas produzidas, foram selecionadas membranas de diversas composições e foi utilizada uma lupa da Marca Olympus, modelo SZ51, com correção de lente ocular de aumento de 40 vezes e um microscópio óptico da marca LEICA, modelo DM500 com lente ocular 13613240, de aumento de 40 vezes. O microscópio permitiu a visualização do tamanho dos poros das membranas pois proporciona uma luz de baixo para cima, já a lupa permitiu a visualização da distribuição e do carvão e do polipropileno ao longo das membranas pois proporciona uma luz de cima para baixo. 
Revista Brasileira de Ciencia, Tecnologia e Inovaçà

Tabela 2 - Composições das membranas e dados operacionais de produção, em ordem de número de membrana.

\begin{tabular}{cccc}
\hline$N^{\circ}$ da membrana & Tempo (Min) & \% de carvão & \% de polipropileno \\
\hline 1 & $4,20 \mathrm{E} 2$ & 15 & 85 \\
\hline 2 & $4,20 \mathrm{E} 2$ & 25 & 75 \\
\hline 3 & $7,80 \mathrm{E} 2$ & 15 & 85 \\
\hline 4 & $7,80 \mathrm{E} 2$ & 25 & 75 \\
\hline 5 & $3,60 \mathrm{E} 2$ & 20 & 80 \\
\hline 6 & $8,40 \mathrm{E} 2$ & 20 & 80 \\
\hline 7 & $6,00 \mathrm{E} 2$ & 13 & 87 \\
\hline 8 & $7,80 \mathrm{E} 2$ & 10 & 90 \\
\hline 9 & $7,80 \mathrm{E} 2$ & 5 & 95 \\
\hline 10 & $6,00 \mathrm{E} 2$ & 7 & 93 \\
\hline 11 & $1,80 \mathrm{E} 3$ & 7 & 93 \\
\hline 12 & $1,80 \mathrm{E} 3$ & 13 & 87 \\
\hline 13 & $4,10 \mathrm{E} 2$ & 10 & 90 \\
\hline 14 & $2,00 \mathrm{E} 3$ & 10 & 90 \\
\hline 15 & $1,20 \mathrm{E} 3$ & 6 & 86 \\
\hline 16 & $1,20 \mathrm{E} 3$ & 14 & 90 \\
\hline 17 & $1,20 \mathrm{E} 3$ & 10 & \\
\hline
\end{tabular}

Para os ensaios de adsorção na fase líquida foi utilizado como adsorvente o corante azul de metileno (AM) da Farmax com volume de 3E-05 e concentração de 1\% em volume. Foi então preparada uma solução estoque com $6,252 \mathrm{E}-03 \mathrm{~mol} / \mathrm{m}^{3}$. A intensidade da coloração da solução de corante é calculada a partir do valor de absorbância, segundo a Lei de Beer. Essa relação entre Absorbância e Concentração é diretamente proporcional ao caminho percorrido pela radiação através do meio $(b)$, e a concentração da espécie absorvente (c), dado na Equação (1), tendo a constante de absortividade (a) como dependente da magnitude das unidades empregadas em $(b)$ e $(c)$ (HOLLER; SKOOG; CROUCH, 2009).

$$
A=a . b . c
$$

Para determinar a concentração de azul de metileno em diferentes soluções, construiu-se sua curva de calibração. Após isso, mediu-se a absorbância destas em um comprimento de onda de $665 \mathrm{~nm}$ usando um espectrofotômetro UV-Vis, marca biospectro, modelo SP-22, utilizando-se como solução de calibração a água destilada.

Em seguida, agitou-se a solução estoque obtida anteriormente e anotou-se sua absorbância como sendo a inicial. Logo após, colocou-se uma membrana dentro de um béquer de $2,5 \mathrm{E}-04 \mathrm{~m}^{3}$ e visando submergir a membrana com a solução estoque preparada anteriormente pipetou-se $2,0 \mathrm{E}-05 \mathrm{~m}^{3}$ da solução dos balões para o béquer. $\mathrm{Em}$ cada béquer, retirou-se em um determinado tempo uma alíquota da solução com a membrana e anotou-se sua absorbância.

Segundo Soares (2014), os valores de concentração no tempo de equilíbrio foram obtidos a partir dos valores de absorbância aplicados à equação da curva de calibração. 
Considerando-se os valores de concentração (Ci) no tempo inicial (ti=0) e a concentração (Cf) no tempo final (equilíbrio da adsorção), calculou-se a eficiência (Porcentagem) da remoção do corante, segundo a Equação 2.

$$
\operatorname{Eficiência}(\%)=\left(\left(C_{i}-C_{f}\right) / C_{i}\right) \cdot 100
$$

\section{RESULTADOS E DISCUSSÃO}

A Figura 1 representa as membranas formadas em cada equipamento. A membrana de polipropileno criada na Mufla ficou porosa, atendendo ao objetivo buscado, como exposto na Figura 1 (a), e em apenas 1,8E02 segundos, o polipropileno havia fundido totalmente. O teste realizado na Estufa provou a inviabilidade do uso deste equipamento para a produção das membranas, pois esta não conseguiu estabilizar-se a uma temperatura tão alta, tornando o tempo de 1,5E03 segundos, insuficiente para fundir a massa de material presente no molde, Figura 1 (b). Por fim, o teste realizado no analisador de umidade via infravermelho também atingiu o objetivo de fundir todo 0 polipropileno para a formação da membrana, formando os poros desejados durante este processo. No entanto, devido à sensibilidade da balança interna ao equipamento, esta poderia ser danificada durante os testes, então se optou por não utilizar este equipamento. Dos três equipamentos utilizados, o ideal para a produção das membranas deste trabalho foi a Mufla, que atendeu ao objetivo de criar uma membrana porosa em pouco tempo.

Figura 1 - Resultados encontrados nos testes em cada equipamento.

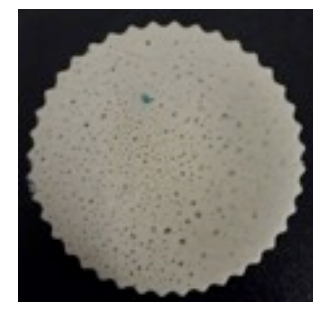

(a) Mufla

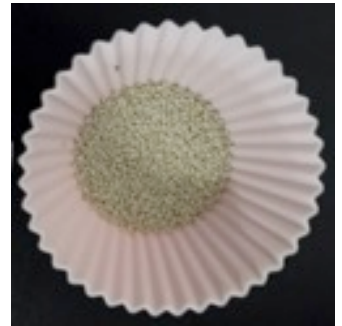

(b) Estufa

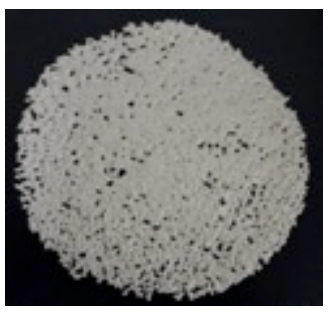

(c) Analisador de umidade

Para a condução de todos os testes fez-se necessária ainda a determinação das condições ideais de operação, utilizando-se polipropileno puro. Para a determinação do tempo ideal de operação e da proporção mássica foram realizados testes variando-se os tempos de permanência das membranas na mufla e as proporções de carvão e polipropileno, conforme a Tabela 2. Alguns dos testes realizados e os resultados obtidos a partir destes são apresentados na Tabela 3. 
Revista Brasileira de Ciencia, Tecnołogia e Inovaçăo

Tabela 3 - Testes realizados utilizando-se polipropileno e carvão, a diferentes tempos de permanência na mufla e frações mássicas.

\begin{tabular}{|c|c|c|}
\hline Imagem & Dados & Conclusão \\
\hline & $\begin{array}{c}\text { 25\% de carvão; } \\
75 \% \text { de PP; } \\
\text { t = } 420 \mathrm{~s}\end{array}$ & $\begin{array}{l}\text { Formaram-se apenas flocos de } \\
\text { polipropileno e carvão. }\end{array}$ \\
\hline
\end{tabular}

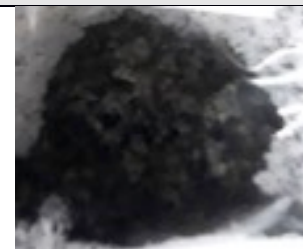

$25 \%$ de carvão;

Ficou muito quebradiça, desfazendo-se, $75 \%$ de PP; observou-se que o carvão se concentrou $\mathrm{t}=780 \mathrm{~s}$ no fundo da membrana e o polipropileno na parte superior.

Membrana 4

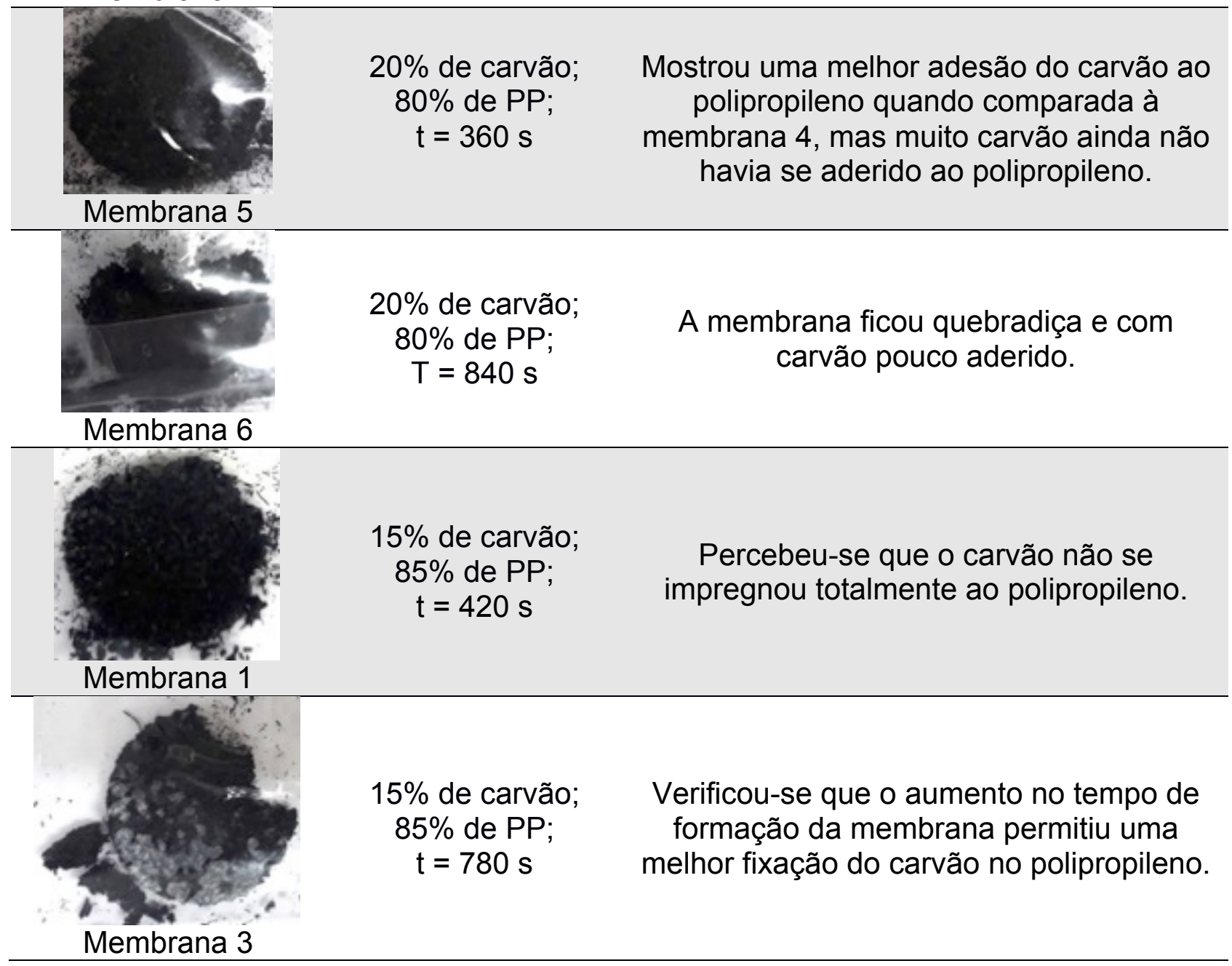


Revista Brasileira de Ciencia, Tecnołogia e Inovaçăo

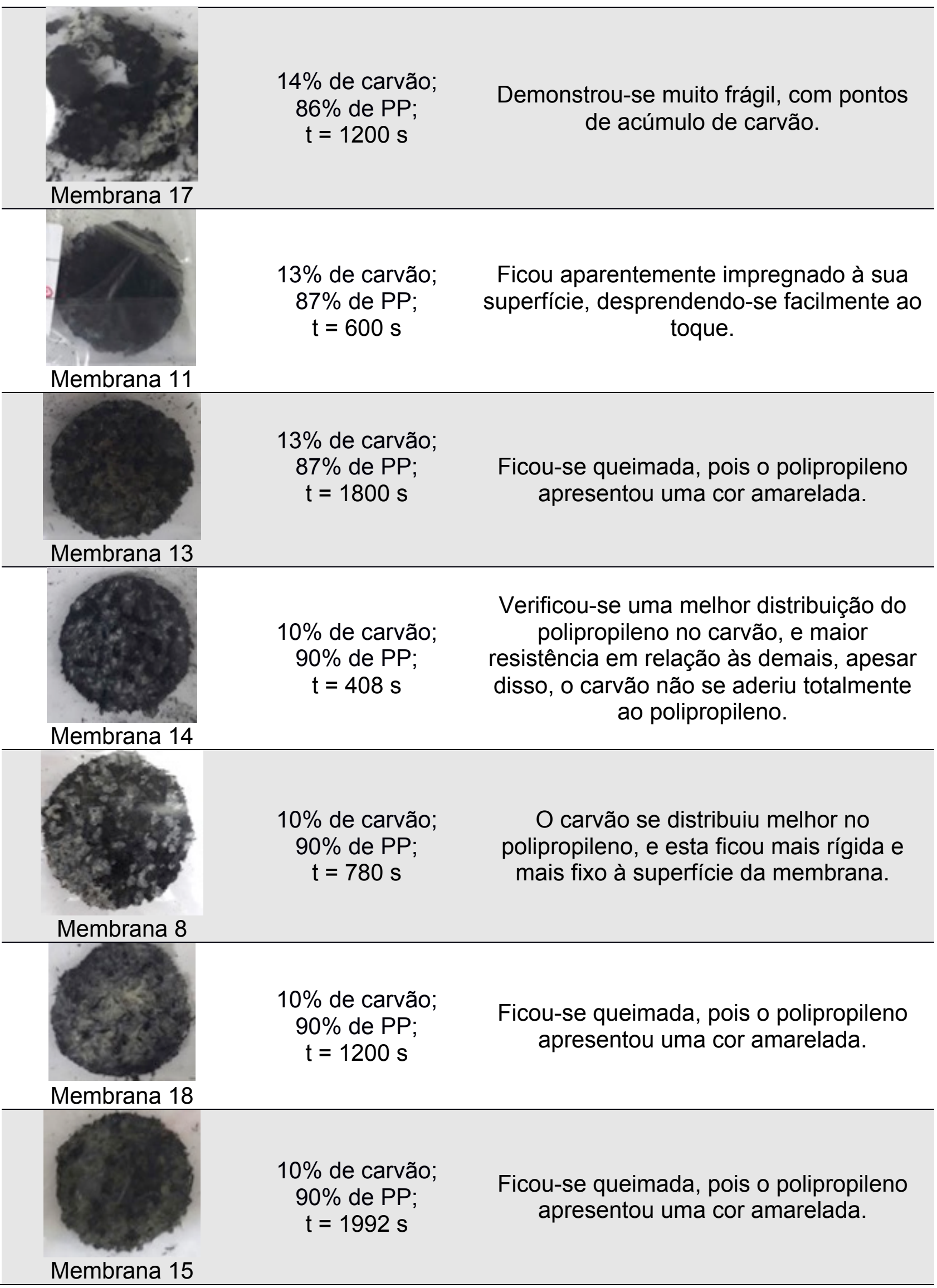




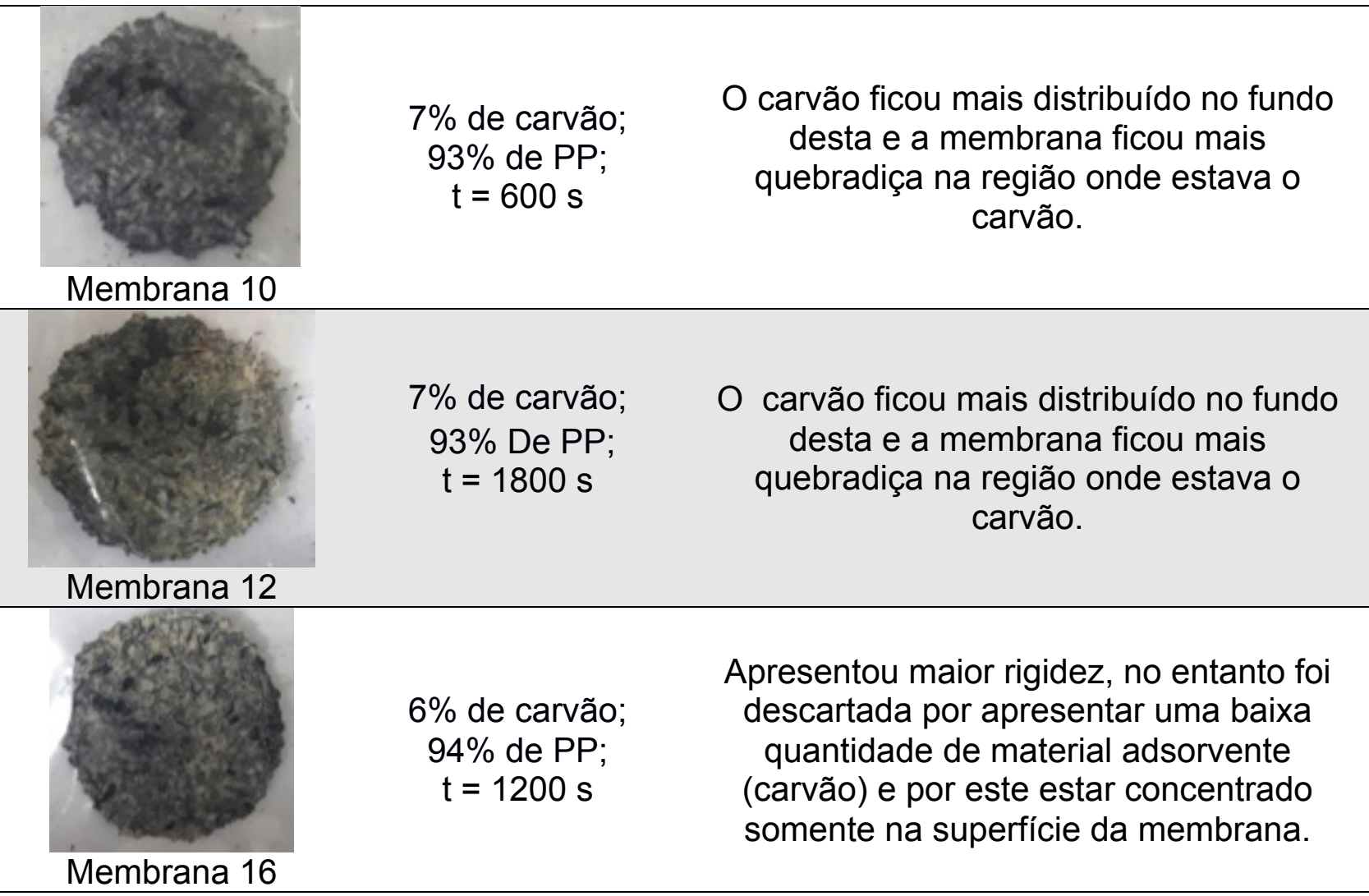

Portanto, a composição ideal para a membrana foi a de $90 \%$ de polipropileno e $10 \%$ de carvão, definida pela membrana 8 , pois esta gerou uma membrana rígida e com o carvão aderido à sua superfície. Além disso, o melhor tempo de formação das membranas na Mufla foi de 780 segundos, suficiente para fundir o polipropileno e gerar aderência do carvão na membrana e, além disso, tempo insuficiente para queimar as membranas.

As análises realizadas nas membranas estão expostas na Tabela 4. Foram selecionadas membranas de composições e tempos diversos para análise visual. Sem ampliação todas as membranas analisadas apresentaram aderência do carvão, com exceção da membrana de número 9. Para esse caso, estima-se que pela alta quantidade de polipropileno, o carvão tenha sido impelido para a superfície superior da membrana.

Com o auxílio da lupa e do microscópio foi possível determinar que o carvão e o polipropileno estão distribuídos ao longo da membrana de forma heterogênea, com alguns pontos de concentração de carvão. Com o auxílio do microscópio, o qual projeta uma luz debaixo da membrana para a superfície desta, foi possível visualizar que a membrana possui poros, também heterogeneamente distribuídos. Desta forma, independente da concentração de carvão e polipropileno, pode-se concluir que a distribuição dos sólidos e dos poros ao longo da membrana é heterogênea, independente da composição.

Analisando-se as réplicas da membrana 8 , nas imagens sem ampliação, observase que o carvão aderiu-se à superfície da membrana. Nota-se ainda, para estas membranas, que via microscópio foi possível visualizar os poros presentes e, para as outras composições, nota-se que os poros são muito maiores, chegando a buracos, o que confirma o fato de que não são ideais para este trabalho. 


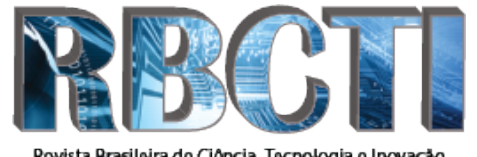

Tabela 4 - Informações sobre as membranas e análises visuais.

\begin{tabular}{|c|c|c|c|c|c|}
\hline Membrana & Composição & $\begin{array}{c}\text { Tempo } \\
\text { (s) }\end{array}$ & Sem ampliar & Lupa & Microscópio \\
\hline Réplica 1 & $\begin{array}{c}90 \% \text { PP } \\
10 \% \text { Carvão }\end{array}$ & 13 & & & \\
\hline Réplica 2 & $\begin{array}{c}90 \% \text { PP } \\
10 \% \text { Carvão }\end{array}$ & 13 & & & \\
\hline 9 & $\begin{array}{c}\text { 95\% PP } \\
5 \% \text { Carvão }\end{array}$ & 13 & & & \\
\hline 10 & $\begin{array}{c}93 \% \text { PP } \\
7 \% \text { Carvão }\end{array}$ & 10 & & & \\
\hline 11 & $\begin{array}{l}\text { 87\% PP } \\
13 \% \text { Carvão }\end{array}$ & 10 & & & \\
\hline 14 & $\begin{array}{l}90 \% \text { PP } \\
10 \% \text { Carvão }\end{array}$ & 6,8 & & & \\
\hline Réplica & $90 \% \mathrm{PP}$ & 13 & & & \\
\hline 3 & 10\% Carvão & & & & \\
\hline
\end{tabular}




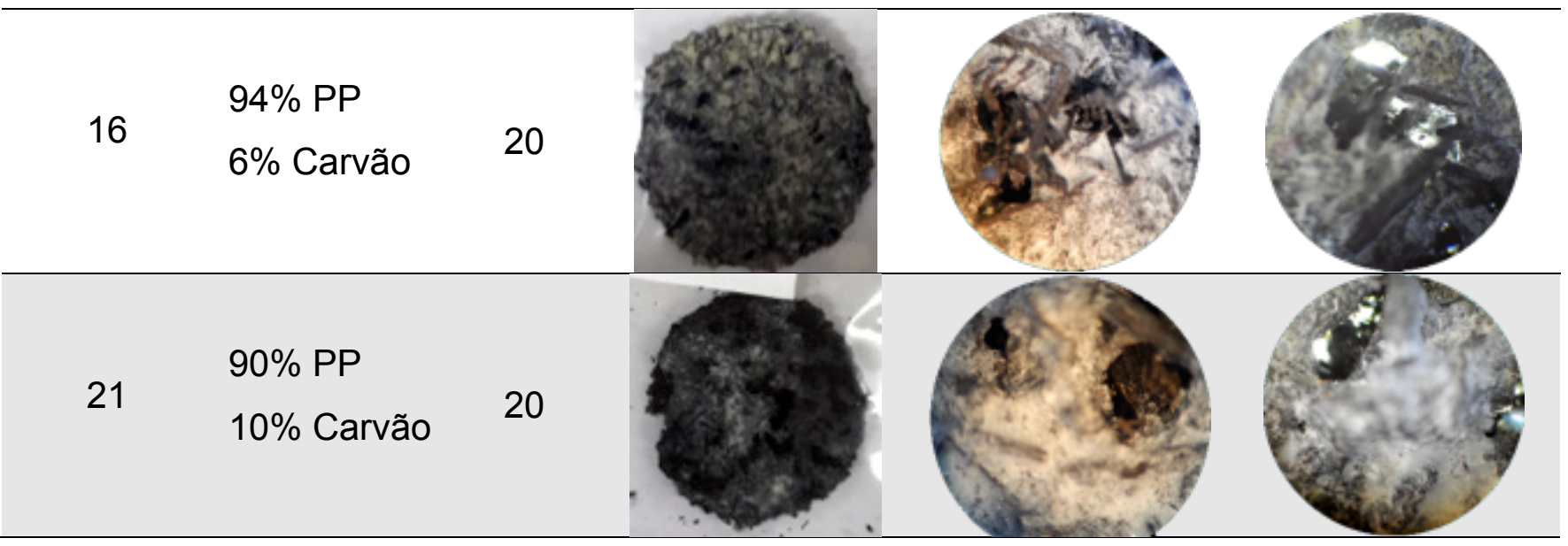

Para os testes de adsorção, inicialmente obteve-se a curva de calibração do azul de metileno (Figura 2), através desta, utilizando-se os valores de absorbância versus concentração de solução.

Figura 2 - Curva de calibração para a solução de azul de metileno.

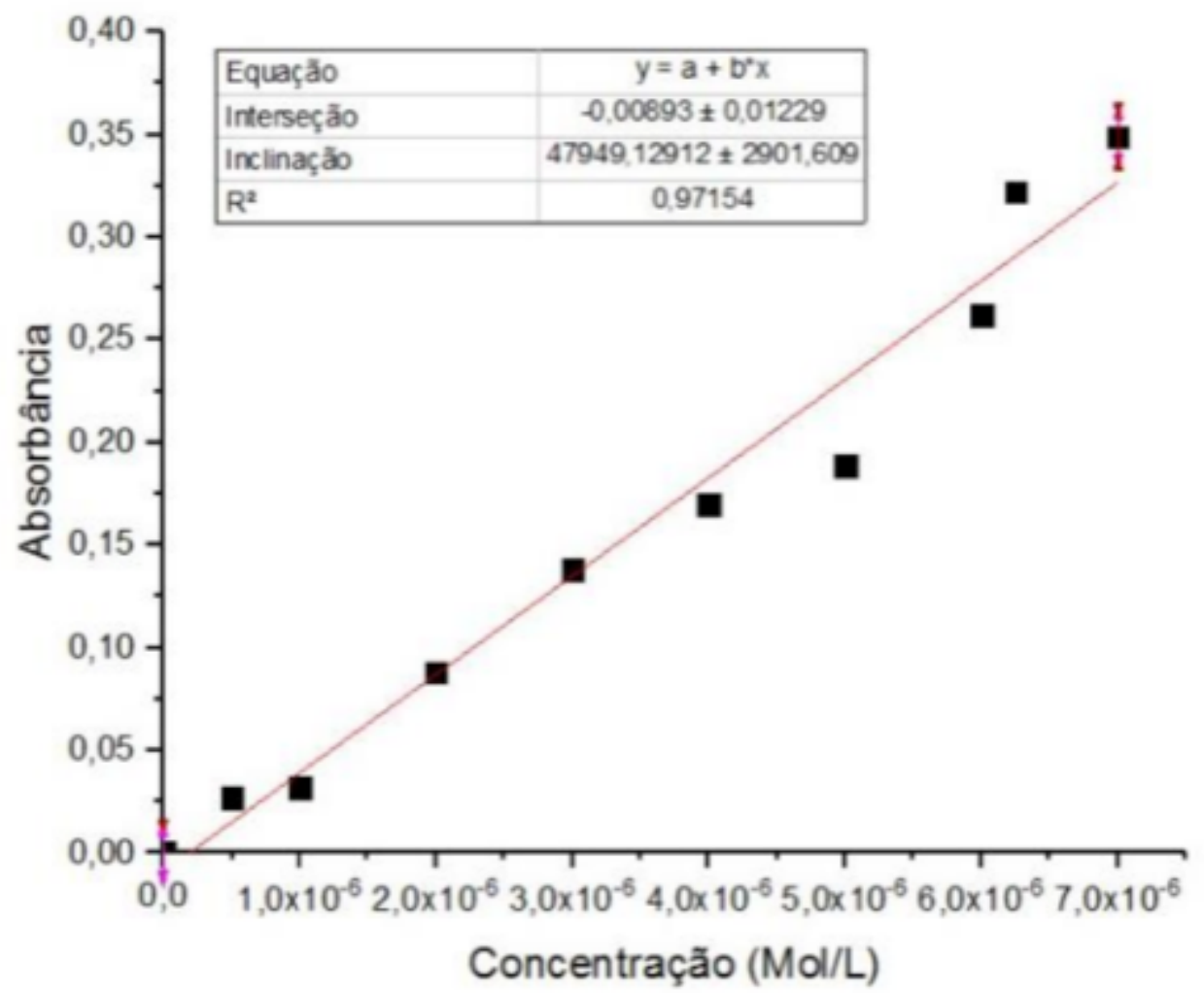

Através dos testes de adsorção, em batelada, realizados para as 16 membranas, réplicas da condição 8 (Composição de $90 \%$ de polipropileno e 10\% de carvão) com azul de metileno em diferentes tempos obteve-se a Tabela 5.

Primeiramente, tentou-se avaliar a influência do tempo na adsorção dessas membranas. A partir dos valores encontrados na Tabela 5 e na Figura 2, notou-se que 
não foi possível determinar essa influência, pois as réplicas apresentam distribuição dos componentes de forma heterogênea, os poros das mesmas se comportaram diferente durante a adsorção do azul de metileno.

Tabela 5 - Testes de adsorção das membranas com azul de metileno.

\begin{tabular}{ccc}
\hline Réplicas & Tempo (s) & Absorbância \\
\hline- & 0 & 0,322 \\
\hline 1 & 300 & 0,288 \\
\hline 2 & 450 & 0,277 \\
\hline 3 & 600 & 0,257 \\
\hline 4 & 750 & 0,277 \\
\hline 5 & 900 & 0,192 \\
\hline 6 & 1050 & 0,230 \\
\hline 7 & 1200 & 0,184 \\
\hline 8 & 1500 & 0,292 \\
\hline 9 & 1800 & 0,293 \\
\hline 10 & 2100 & 0,285 \\
\hline 11 & 2400 & 0,271 \\
\hline 12 & 2700 & 0,250 \\
\hline 13 & 3000 & 0,200 \\
\hline 14 & 3300 & 0,249 \\
\hline 15 & 3600 & 0,182 \\
\hline 16 & 3900 & 0,211 \\
\hline
\end{tabular}

Através dos dados encontrados pela curva de calibração do azul de metileno, foi possível determinar a eficiência de adsorção de cada membrana por meio da Equação 1. Os valores encontrados estão expressos na Tabela 6. Por intermédio desses valores, foi possível verificar que há uma remoção do corante na ordem de $40 \%$ nas réplicas $5,7,13$ e 15, ou seja, estas membranas apresentaram o melhor resultado de adsorção.

Assim, por intermédio dos dados obtidos na Tabela 6, constatou-se a maior eficiência na remoção de corante das membranas sintetizadas foi em torno de $40 \%$. Estima-se que o baixo valor encontrado é devido à realização dos testes de adsorção sem agitação (por conta da fragilidade da membrana), o que limita a transferência de massa entre a membrana e a solução com corante, resultando em uma menor adsorção.

Tabela 6 - Concentração e eficiência de adsorção das membranas.

\begin{tabular}{ccc}
\hline Membranas & $\begin{array}{c}\text { Concentração } \\
\left(\mathrm{mol} / \mathrm{m}^{3}\right)\end{array}$ & $\%$ \\
\hline- & $6,6 \mathrm{E}-06$ & 0 \\
\hline 1 & $5,8 \mathrm{E}-06$ & 10,9 \\
\hline 2 & $5,6 \mathrm{E}-06$ & 14,4 \\
\hline 3 & $5,2 \mathrm{E}-06$ & 20,8 \\
\hline 4 & $5,6 \mathrm{E}-06$ & 14,4 \\
\hline 5 & $3,8 \mathrm{E}-06$ & 41,5 \\
\hline 6 & $4,6 \mathrm{E}-06$ & 29,4 \\
\hline
\end{tabular}


Revista Brasileira de Ciencia, Tecnołogia e Inovaçăo

\begin{tabular}{rll}
\hline 7 & $3,6 \mathrm{E}-06$ & 44,1 \\
\hline 8 & $5,9 \mathrm{E}-06$ & 9,60 \\
\hline 9 & $5,9 \mathrm{E}-06$ & 9,30 \\
\hline 10 & $5,8 \mathrm{E}-06$ & 11,8 \\
\hline 11 & $5,5 \mathrm{E}-06$ & 16,3 \\
\hline 12 & $5,0 \mathrm{E}-06$ & 23,0 \\
\hline 13 & $4,0 \mathrm{E}-06$ & 39,0 \\
\hline 14 & $5,0 \mathrm{E}-06$ & 23,4 \\
\hline 15 & $3,6 \mathrm{E}-06$ & 44,8 \\
\hline 16 & $4,2 \mathrm{E}-06$ & 35,4 \\
\hline
\end{tabular}

\section{CONCLUSÕES}

Dos equipamentos analisados para a confecção das membranas, a Mufla foi o equipamento que em pouco tempo e a uma temperatura próxima à de fusão do polipropileno, conseguiu prover uma membrana aparentemente porosa com o todo o polipropileno presente fundido.

Para a determinação das condições ótimas de operação foi utilizado polipropileno puro, testando-se composições e tempos diversos, e definida a temperatura de operação próxima à de fusão do polipropileno. Dos tempos e composições testadas, as que apresentaram membranas com carvão aderido, poros aparentes e polipropileno fundido foram as produzidas com: 13 minutos de permanência na Mufla e $90 \%$ de polipropileno e $10 \%$ de carvão na composição.

Analisou-se membranas de diversas composições e tempos e para todas foi possível concluir que a distribuição dos componentes ao longo da membrana é totalmente heterogênea. Além disso, foi possível visualizar alguns poros nas membranas, os quais também estão dispersos, criando nas membranas um padrão totalmente heterogêneo.

Inicialmente, obteve-se a curva de calibração para a solução com azul de metileno produzida. Nos testes de adsorção em batelada, não foi possível perceber a influência do tempo na remoção do azul de metileno, pois observou-se que os poros das mesmas se comportaram diferentes durante a adsorção desse corante. Além disso, constatou-se a maior eficiência na remoção de corante das membranas sintetizadas na mesma condição foi em torno de $40 \%$. Estima-se que o valor tenha sido baixo pois não houve agitação nos testes de adsorção, limitando a transferência de massa no processo.

\section{REFERÊNCIAS}

BHATNAGAR, A.; HOGLAND, W.; MARQUES, M.; SILLANPÄÄ, M. An overview of the modification methods of activated carbon for its water treatment applications.

Chemical Engineering Journal, v. 219, p. 499-511, 2013.

BHATNAGAR, A.; SILLANPÄÄ, M. Utilization of agro-industrial and municipal waste materials as potential adsorbents for water treatment: A review. Chemical Engineering Journal, [S.I.], v. 157, p. 277-296, mar. 2010. 
BHATTACHARYYA, K. G.; GUPTA, S. S. Pb(II) uptake by kaolinite and montmorillonite in aqueous medium: Influence of acid activation of the clays. Colloids and Surfaces A: Physicochemical and Engineering Aspects. 2006.

BORGES, C; HABERT, A; NOBREGA, R. Processo de separação por membranas. Rio de Janeiro: E-papers, p.9, 2006.

CLAUDINO, A. Preparação de carvão ativado a partir de turfa e sua utilização na remoção de poluentes. Dissertação (Mestrado em Engenharia Química) - Universidade Federal de Santa Catarina, Florianópolis. 2003

COSTA, R. C. C.; MOURA, F. C. C.; ARDISSON J. D.; FABRIS, J.D.; LAGO, R. M. Highly active heterogeneous Fenton-like systems based on Fe0/Fe304 composites prepared by controlled reduction of iron oxides. Applied Catalysis B: Environmental, v. 83, n. 1-2, p. 131-139, Sept. 2008

FREITAS, L; BUENO, S. Carvão ativo: Breve Histórico de sua eficiência na retenção de Fármacos. p. 2-3, 2013.

GHOSH, D.; BHATTACHARYYA, K. G. Adsorption of methylene blue on kaolinite. Applied Clay Science. 2002.

GIUSTO, L. Obtenção de carvão ativado a partir de fuligem de bagaço de cana-deaçúcar para aplicações ambientais. Dissertação (Mestrado em Engenharia Química) Universidade Federal de Alfenas, Florianópolis. p. 83, 2015.

HOLLER, F. J.; SKOOG, D. A.; CROUCH, S. R. Princípios de Análise Instrumental. 6. ed. Porto Alegre: Bookman, 2009.

INDUPROPIL. O que é polipropileno?. Disponível em:

$<$ http://www.indupropil.com.br/conteudo/0,2095_o-que-e-polipropileno>. Acesso em: 15 fev. 2018.

MCKAY, G. The removal of dye colours from aqueous solutions by adsorption on low-cost materials. Water, Air, \& Soil Pollution. 1999.

PAULINO, A. T. Produção de adsorventes não-convencionais e aplicação na remediação de águas e efluentes industriais. 2008. 181. Tese (Doutorado em Ciências) Departamento de Química, Centro de Ciências Exatas da Universidade Estadual de Maringá, Maringá, 2008.

PEREIRA, E. I. " Produção de carvão ativado a partir de diferentes precursores utilizando $\mathrm{FeCl}_{3}$ como o agente ativante". Dissertação (Mestrado em Agroquímica) Universidade Federal de Lavras, MG. 2010.

RAFATULLAH, M.; SULAIMAN, o.; HASHIM, R.; AHMAD, A. Adsorption of methylene blue on low-cost adsorbents: A review. Journal of Hazardous Materials, v. 177, n. 13, p. 70-80, 2010. 
RESO SOLUÇÕES AMBIENTAIS. Polipropileno : Embalando o Mundo com Eficiência e Praticidade. Disponível em: <http://resoambiental.com/2015/06/polipropileno-embalandoo-mundo-com-eficiencia-e-praticidade/>. Acesso em: 15 fev. 2018.

ROYER, B. Remoção de corantes têxteis utilizando casca de semente de Araucária angustifolia como biosorvente. Tese (Mestrado em Química) Universidade Federal do Rio Grande do Sul, Porto Alegre, 2008.

SENTHILKUMAAR, S.; VARADARAJAN, P. R.; PORKODI, K.; SUBBHURAAM, C.V. Adsorption of methylene blue onto jute fiber carbon: kinetics and equilibrium studies. Journal of Colloid and Interface Science. 2005.

XING, Y., LIU, Z. Enhanced adsorption of methylene blue by EDTAD-modified sugarcane bagasse and photocatalytic regeneration of the adsorbent. Desalination, 2010.

YI, J.; ZHANG, L. Removal of methylene blue dye from aqueous solution by adsorption onto sodium humate/polyacrylamide/clay hybrid hydrogels. Bioresource technology, v. 99, n. 7, 2008.

ZEN, H.; GERALDES, A. N.; PARRA, D.; GERALDO, A. B. C.; ARAUJO, S. G.; LUGAO, A.; LINARDI, M. Caracterização de filmes de polipropileno modificados para uso como membrana trocadora de prótons. Congresso Brasileiro de Engenharia e Ciência dos Materiais. Foz do Iguaçu, PR. 2006.

Recebido em: 02/12/2018

Aprovado em: 08/02//2019 